\title{
¿Cuál es su abordaje?
}

\section{Which is the approach?}

\section{Isidoro Rubio-Correa*, Damián Manzano-Solo de Zaldívar, Raúl González-García y Florencio Monje-Gil}

Servicio de Cirugía Oral y Maxilofacial, Hospital Infanta Cristina, Badajoz, España

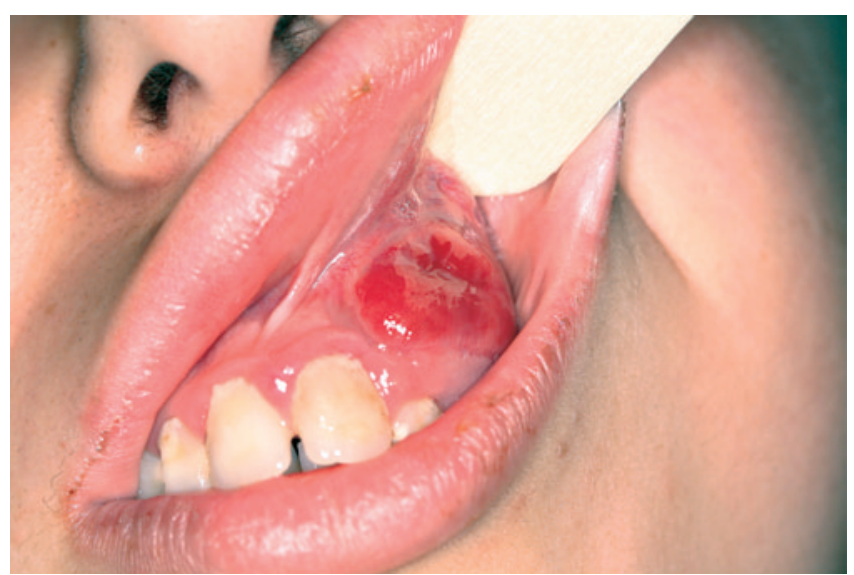

Figura 1 - Imagen de la lesión.

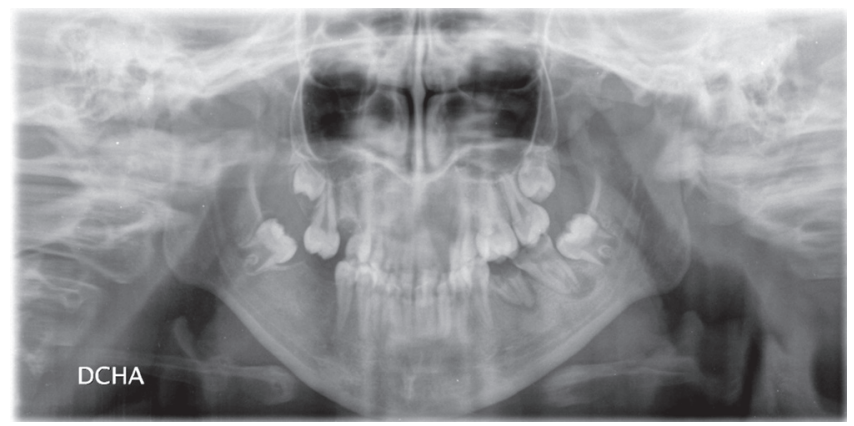

Figura 2 - Ortopantomografía en la que se aprecia defecto lítico a nivel del hemimaxilar izquierdo.

Mujer de 16 años de edad, sin ningún antecedente clínico de interés. Acude a la consulta derivada por el odontoestomatólogo de zona, debido a que presenta una lesión de varios meses de evolución en la encía adherida del segundo cuadrante (fig. 1), cuyo tamaño, según la paciente, no ha aumentado en las últimas semanas. Clínicamente está asintomática, sin dolor a la palpación. A la exploración física, dicha

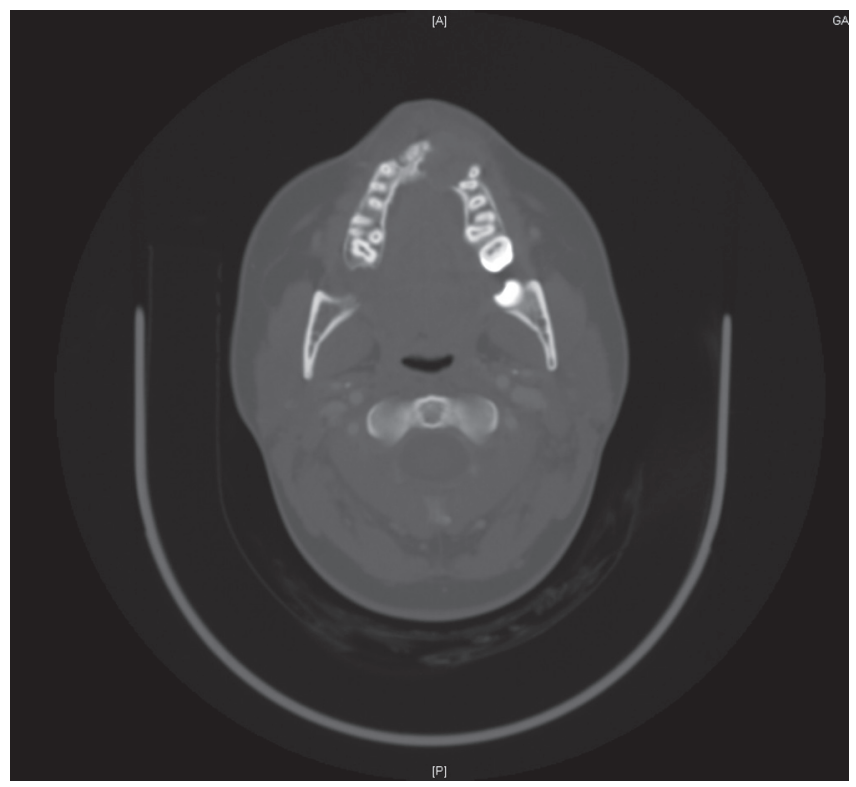

Figura 3 - Corte axial de tomografía computarizada en la que se puede apreciar la lesión y la destrucción causada en el maxilar por ella.

lesión es de color rojizo, consistencia blanda y carnosa. Causa una importante prominencia y abultamiento, tanto por vestíbulo como por palatino, así como la movilidad de las piezas 22 y 23. La analítica solicitada en su centro de salud es rigurosamente normal. Como pruebas de imagen, acude con una ortopantomografía (fig. 2), en la que se aprecia importante defecto óseo coincidiendo con la zona de la lesión, cordales

\footnotetext{
${ }^{*}$ Autor para correspondencia.

Correo electrónico: Isirc84@gmail.com (I. Rubio Correa).
} 


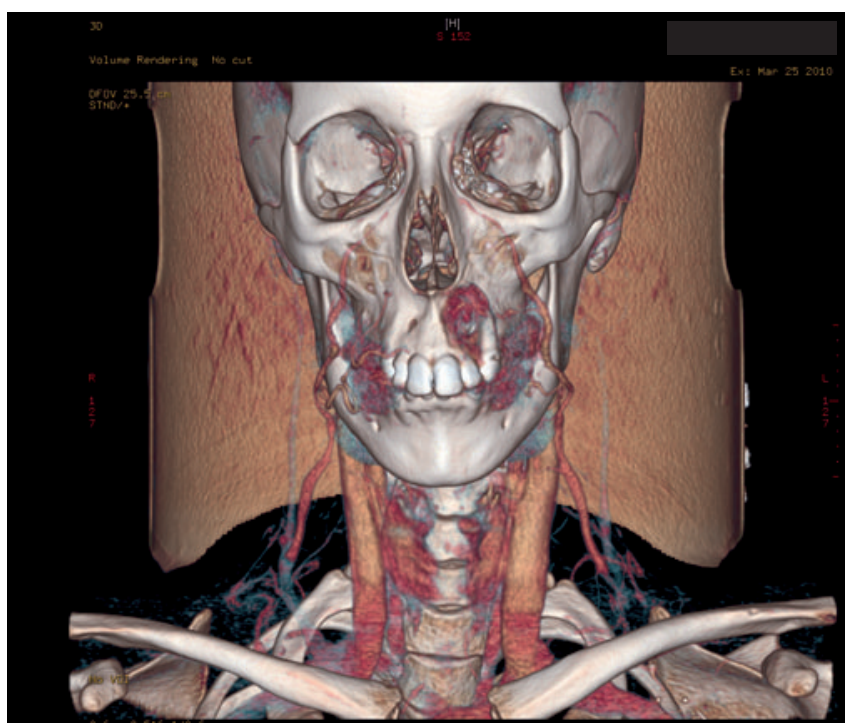

Figura 4 - Reconstrucción coronal tridimensional a partir de la tomografía computarizada previa.

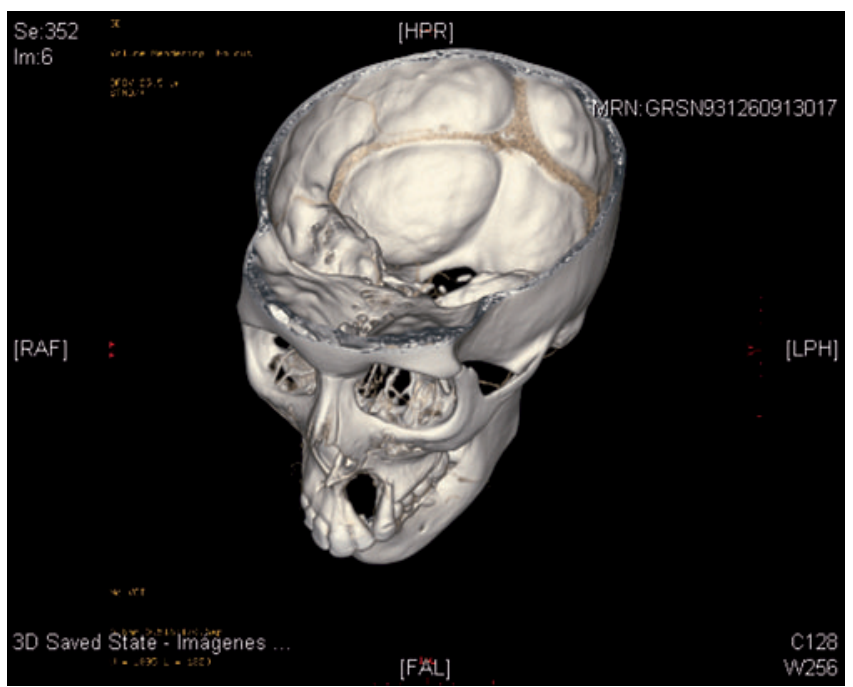

Figura 5 - Visión del defecto creado por la lesión a través de una reconstrucción coronal oblicua tridimensional a partir de la tomografía computarizada previa.

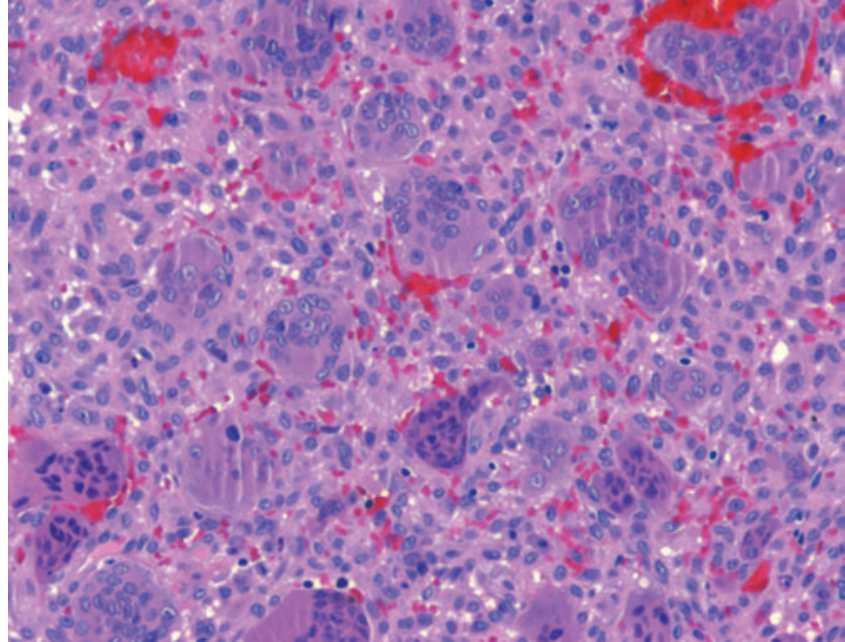

Figura 6 - Tinción de hematoxilina-eosina en la que se aprecian los conglomerados de células gigantes multinucleadas.

18, 28, 38 y 48 incluidos, así como restos radiculares de las piezas 16 y 36, y lesiones periapicales en relación con las piezas 36 y 37. Una vez vista por primera vez en consulta, se solicita tomografía computarizada facial con cortes axiales y coronales, que pone de manifiesto el defecto óseo visualizado en la ortopantomografía (fig. 3), así como reconstrucciones tridimensionales (figs. 4 y 5). Además, se realiza biopsia de ésta, en la que se haya una intensa proliferación de fibroblastos y células gigantes multinucleadas, informada como "granuloma de células gigantes" (fig. 6). 